\title{
Perception of anesthesia safety and postoperative symptoms of surgery patients in Ho Chi Minh City, Vietnam: a pioneering trial of postoperative care assessment in a developing nation
}

\author{
Kumiko Soejima $\cdot$ Aya Goto $\cdot$ Phan Ton Ngoc Vu $\cdot$ Le Huu Thien Bien • \\ Nguyen Quang Vinh • Pham Nghiem Minh • Gautam A. Deshpande • \\ Seiji Yasumura • Akira Fukao
}

Received: 1 June 2009/Accepted: 15 April 2010/Published online: 8 May 2010

(C) The Japanese Society for Hygiene 2010

\begin{abstract}
Objectives Vietnamese patients' views on healthcare are changing as surgical interventions become more commonplace, but their views on perioperative care have remained largely unstudied during this period of rapid change. This study assesses Vietnamese patients' impression of anesthesia safety and postoperative pain in relation
\end{abstract}

K. Soejima $\cdot$ A. Fukao

Department of Public Health, Faculty of Medicine,

Yamagata University, Yamagata, Japan

K. Soejima $\cdot$ A. Goto $\cdot$ S. Yasumura

Department of Public Health, School of Medicine,

Fukushima Medical University, Fukushima, Japan

Present Address:

K. Soejima $(\bowtie) \cdot$ G. A. Deshpande

Center for Clinical Epidemiology,

St. Luke's Life Science Institute,

St. Luke's International Hospital,

10-1 Akashi-cho, Chuo-ku, Tokyo 104-0044, Japan

e-mail:kmkato508@hotmail.com

P. T. N. Vu

Department of Anesthesia, University Medical Center,

Ho Chi Minh City, Vietnam

L. H. T. Bien

Department of ICU, University Medical Center,

Ho Chi Minh City, Vietnam

N. Q. Vinh

Hanh Phuc Women and Children Hospital Project,

Hanh Phuc Women and Children Hospital,

Ho Chi Minh City, Vietnam

P. N. Minh

Department of Genetics,

Tu Du Obstetrical and Gynecological Hospital,

Ho Chi Minh City, Vietnam to clinical outcomes with the aim of improving patientcentered perioperative care.

Methods The study cohort consisted of 180 hospitalized patients who were followed for $24 \mathrm{~h}$ following abdominal surgery. The assessments of these patients on the use of anesthesia and postoperative pain were measured by means of a 5-point Likert scale survey. Perioperative events were recorded on standardized forms by medical staff. The relationship between relevant factors affecting the patients' perceptions of anesthesia safety, postoperative symptoms, and pain was examined using multiple logistic regression analysis.

Results The perception of a low level of anesthesia safety by 105 patients (59\%) was associated with a low satisfaction in terms of preoperative anesthesia education [odds ratio (OR) 15.03], poor interaction with family (OR 21.80), and absence of perioperative adverse effects (OR 6.10). The occurrence of three or more postoperative symptoms (59\%) was associated with a surgery $\geq 3 \mathrm{~h}$ (OR 2.00). Severe pain at $2 \mathrm{~h}(25 \%)$ post-surgery was associated with male gender (OR 2.08) and open surgery (OR 3.30), no reduction in pain at $24 \mathrm{~h}(51 \%)$ was associated with female gender (OR 2.08), and experiencing as much or more pain than expected (46\%) was associated with blood loss $\geq 100 \mathrm{ml}$ (OR 1.04) and low satisfaction with staff communication (OR 1.90).

Conclusion Our results suggest that facilitating patients' communication with staff and families and paying attention to gender differences in pain management are important factors to take into consideration when the aim is to improve perioperative care in the rapidly developing healthcare environment of Vietnam.

Keywords Anesthesia safety · Patient satisfaction . Postoperative pain 


\section{Introduction}

The proper use of anesthesia is important for reducing the pain and anxiety of patients undergoing surgery. In order to improve the quality of such care, it is essential to evaluate perioperative services [1]. While quality assessments are becoming increasingly more common in developed nations, data on patient-centered evaluations in developing countries are limited $[2,3]$. Patients' perioperative conditions are influenced not only by medical factors, such as disease pathophysiology, anesthetic intervention, and surgical procedures, but also by patients' perception of the care they receive [4]. The relief of symptoms, promotion of satisfaction with the medical experience, and promotion of a feeling of well-being are among the most important goals of care, and are of central concern to patients and doctors alike [5]. Therefore, any evaluation of medical service must involve both clinical factors and the medical experience as perceived by the patient, i.e., the patient's subjective perception of the medical experience.

Patient satisfaction and pain assessment largely depend on cultural norms and individual expectations. Consequently, measurements and/or assessments of patient satisfaction and pain cannot be reliably generalized across cultures. A recent study by Carragee and colleagues [6] demonstrated that Vietnamese and American patients reported different levels of pain even with similar surgical procedures and anesthetic methods, ostensibly due to differences in cultural conditioning. Due to the recent introduction of various modern interventions and methods in resource-limited countries [7,8], the importance of comprehensive and multifaceted medical service evaluations is increasing.

Similar to much of Asia, Vietnam is not an exception in experiencing rapid economic growth and improvements in healthcare, resulting in dramatic changes in medical practice and views on medical care by both providers and patients. According to hospital statistics of the University Medical Center (UMC), a hospital affiliated with the University of Medicine and Pharmacy, Ho Chi Minh City in Vietnam, the annual number of surgeries performed under anesthesia increased from 5,500 cases in 2003 to 13,400 cases in 2005 . The most common type of operation was abdominal surgery, which comprised $48 \%$ of all surgeries performed in 2005. Surgical methods are also becoming more advanced; in 2005, 30\% of all abdominal surgeries, for example, were done with laparoscopy. In addition, many hospitals with Western facilities and healthcare practices have been established in the last decade, and providers are becoming more aware of patientcentered care nationwide [9].

Despite these meteoric changes in healthcare, very little effort has been expended to evaluate anesthetic care from both the clinical and patients' perspectives in the Vietnamese healthcare environment. In order to gain a better understanding of the factors relevant to improving patientcentered perioperative care, we conducted a study among abdominal surgery patients at UMC in Ho Chi Minh City with the following specific objectives: (1) to assess surgical and anesthesia outcomes and (2) to assess the clinical and sociodemographic factors associated with the perception of anesthesia safety and postoperative symptoms, including pain.

\section{Methods}

This was a hospital-based epidemiologic study. Patients undergoing gastrointestinal tract (lower esophagus to rectum) surgery were recruited between October 2006 and February 2007. Patients $<15$ years of age and emergency cases were excluded. Those who gave informed consent were registered and followed for $24 \mathrm{~h}$ post-surgery. The study was approved by the ethics committees of Yamagata University Faculty of Medicine and Fukushima Medical University, and the chancellor of the University of Medicine and Pharmacy, Ho Chi Minh City.

Data were collected using structured questionnaires that consisted of sections answered by anesthesiologists, recovery room staff, and patients, respectively. The selection of questionnaire items was based primarily on the survey tool developed by Morgan et al. [10] for assessing perioperative satisfaction among women undergoing caesarean section. Elements of other previous survey-based studies that aimed to improve patients' perioperative experience were also incorporated into our questionnaires [11-15]. The questionnaires were first developed in English through discussion with local physicians and subsequently translated into Vietnamese and then backtranslated into English. The original and back-translated versions were compared to assess the accuracy of the translation. We validated selected questionnaire items by verifying patients' answers with data from the medical chart and comparison with other indicators. Prior to the main survey, we conducted a pilot study for 1 week in August 2006 at UMC with 12 patients to test the quality of the questionnaire, train the survey staff, and confirm the feasibility of the survey protocol. We set an optimal sample size of 180 , referring to calculations based on the binomial distribution of a reported occurrence of insufficient postoperative pain control among Vietnamese patients [6] and considering a balance between the tightness of the calculated $95 \%$ confidence interval (CI) and the feasibility of the survey.

Eight anesthesiologists recorded patients' baseline medical information, medical procedures performed, and 
any treatment for immediate sequelae of anesthesia or surgical interventions, including pain control, on the day of the surgery. All surgical patients were kept in the recovery room for approximately the first $24 \mathrm{~h}$ post-surgery prior to their return to the surgical wards; their interaction with their families was limited during this time. The recovery room staff (4 doctors and 8 nurses) recorded each patient's postoperative condition during this period and, at $24 \mathrm{~h}$, data were recorded on each patient's subjective perception of surgical pain, postoperative symptoms, and the care they had received. In terms of objective data, in response to a patient's pain, any changes in dose or frequency of analgesics was recorded by the healthcare staff.

The following baseline patient characteristics were obtained from medical records by the anesthesiologists and recovery room staff: age, sex, American Society of Anesthesiologists (ASA) classification, medical history, smoking status, and alcohol consumption. Anesthetic and surgical factors, including diagnosis, surgical location, surgical procedure, types of anesthesia provided, duration of surgery, amount of blood loss, pharmacotherapy used, perioperative adverse effects, analgesic medication, and resting surgical pain $2 \mathrm{~h}$ after surgery, were recorded.

The following information was self-reported by patients: education, occupation, medical insurance status, postoperative symptoms, surgical pain $24 \mathrm{~h}$ after surgery, and severity of actual pain compared to expected pain. Using a 5-point Likert scale, the patients were also asked to evaluate their perioperative care in terms of their perception of the safety of receiving anesthesia and their satisfaction with (1) the preoperative education they were given about the anesthesia, (2) their communication with the medical staff, and (3) their interaction with their families before and after surgery. Postoperative symptoms included surgical pain, sore throat, hoarseness, drowsiness, headache, lumbar pain, shoulder pain, dizziness, fever, and nausea or vomiting. Subjective reporting of these types of symptoms has been validated in previous studies [14, 16]. The level of pain was measured using a standard six-level face-scale score using original pictures developed by Wong and Baker [17].

\section{Statistical analysis}

All data were recorded using Access database software (Microsoft, Redmond, WA) and analyzed with SPSS standard version software (SPSS Japan, Tokyo, Japan). First, descriptive analyses were conducted to identify the basic background characteristics of the patients and anesthesia outcomes. Key outcome measurements were: complications with epidural anesthesia, perioperative adverse effects, patients' evaluation of care they received, postoperative symptoms, and pain after surgery. Second, logistic regression analyses were conducted to examine factors associated with (1) feeling less safe with the anesthesia, (2) total number of postoperative symptoms, (3) severe pain at $2 \mathrm{~h}$ after surgery, (5) no reduction in pain between 2 and $24 \mathrm{~h}$ after surgery, and (5) feeling pain approximately equal to or more than expected. Significant variables in bivariate analyses were entered into the multivariate analyses.

All dependent variables were dichotomized as follows after confirming their distributions: the total number of postoperative symptoms ( $\leq 2$ vs. $\geq 3$ ), pain at $2 \mathrm{~h}$ [mildmoderate pain (levels 1-3) vs. severe pain (levels 4-6)], recovery from pain (recovered vs. not recovered, worsened, or no change), and pain expectation (less than expected vs. equal to or more than expected). Recovery from pain was defined as the difference between pain scale scores at 2 and $24 \mathrm{~h}$. In terms of a feeling of safety with anesthesia, only the two highest levels (agree vs. strongly agree) were compared as due to the overall high scoring rate, exclusion of the three lowest levels resulted in the exclusion of only three of 178 subjects from the analysis.

With respect to dichotomized independent variables, 15 items were entered into the analysis of postoperative symptoms: sociodemographic characteristics (age, sex, medical insurance coverage, current smoking and drinking status) and surgical and anesthetic factors (ASA classification, surgical location, surgical procedure, types of anesthesia, evidence of malignancy, duration of surgery, amount of blood loss, complications with epidural anesthesia, perioperative adverse events, and opioid use). In the analyses of the other four outcomes, five additional variables were entered: sociodemographic characteristics (education, occupation) and patients' views (satisfaction with preoperative anesthesia information, communication with medical staff, interaction with family).

\section{Results}

In total, 180 consecutive patients were enrolled in this study. There were no refusals, but two patients did not complete the survey due to coma and death, respectively; the available data for these patients were included in the final analyses. The baseline characteristics of the patient cohort are shown in Table 1. Table 2 presents the data on anesthesia and surgical outcomes, patients' attitudes towards anesthesia, and postoperative symptoms, respectively. Complications with epidural anesthesia and perioperative adverse effects were reported by the medical staff for 17 and $67 \%$ of the patients, respectively. Notably, $98 \%$ of patients agreed with the statement that they felt safe regarding anesthesia. In terms of symptoms, $59 \%$ of 
Table 1 Baseline characteristics of patient cohort
${ }^{\text {a }}$ Total patient cohort $(n)=180$ patients. Discrepancy in the number of patients in some categories is due to two patients being unable to complete the survey as a result of poor postoperative condition

b Stable income defined as salaried employees: government employee, office worker, and others. Unstable income includes non-salaried occupations, such as housewife, unemployed, farmer, fisherman, blue collar worker, selfemployed worker, and others

\begin{tabular}{|c|c|c|}
\hline Baseline characteristics & $n(\%)^{\mathrm{a}}$ & Median (minimum, maximum) \\
\hline \multicolumn{3}{|l|}{ Sociodemographic characteristics } \\
\hline Age (years) & & $57(16,86)$ \\
\hline $16-39$ & $14(7.8)$ & \\
\hline $40-64$ & $105(58.3)$ & \\
\hline$\geqq 65$ & $61(33.9)$ & \\
\hline \multicolumn{3}{|l|}{ Sex } \\
\hline Male & $100(55.6)$ & \\
\hline Female & $80(44.4)$ & \\
\hline \multicolumn{3}{|l|}{ Education } \\
\hline None up to primary school & $69(38.3)$ & \\
\hline Higher than primary school & $109(61.7)$ & \\
\hline \multicolumn{3}{|l|}{ Occupation } \\
\hline Work with stable income ${ }^{b}$ & $25(14.0)$ & \\
\hline Work with unstable income & $153(86.0)$ & \\
\hline \multicolumn{3}{|l|}{ Medical insurance coverage } \\
\hline Yes & $21(11.8)$ & \\
\hline No & $157(88.2)$ & \\
\hline \multicolumn{3}{|l|}{ Surgical and anesthetic characteristics } \\
\hline \multicolumn{3}{|c|}{ American Society of Anesthesiologists (ASA) classification } \\
\hline I-II & $149(82.8)$ & \\
\hline III or higher & $31(17.2)$ & \\
\hline \multicolumn{3}{|l|}{ Malignancy } \\
\hline Malignant & $149(82.8)$ & \\
\hline Benign & $31(17.2)$ & \\
\hline \multicolumn{3}{|l|}{ Medical history } \\
\hline \multicolumn{3}{|l|}{ Cardiovascular disease } \\
\hline Yes & $53(29.4)$ & \\
\hline No & $127(70.6)$ & \\
\hline \multicolumn{3}{|l|}{ Pulmonary disease } \\
\hline Yes & $28(15.6)$ & \\
\hline No & $152(84.4)$ & \\
\hline \multicolumn{3}{|l|}{ Endocrine disease } \\
\hline Yes & $13(7.2)$ & \\
\hline No & $167(92.8)$ & \\
\hline \multicolumn{3}{|l|}{ Surgical area } \\
\hline Upper gastro-intestinal (GI) tract \pm lower GI tract & $93(51.7)$ & \\
\hline Lower GI tract & $87(48.3)$ & \\
\hline \multicolumn{3}{|l|}{ Types of surgical procedures } \\
\hline Laparoscopic surgery & $45(25.0)$ & \\
\hline Open surgery & $135(75.0)$ & \\
\hline \multicolumn{3}{|l|}{ Types of anesthesia } \\
\hline General (inhalational) anesthesia & $47(26.1)$ & \\
\hline General (inhalational) + epidural anesthesia & $133(73.9)$ & \\
\hline Duration of surgery (min) & & $180(15,470)$ \\
\hline Amount of blood loss (ml) & & $100(5,1000)$ \\
\hline
\end{tabular}

patients reported three or more postoperative symptoms, and $12 \%$ reported experiencing more pain than expected, with 25 and $9 \%$ of these reporting moderate/severe pain at
2 and $24 \mathrm{~h}$ post-surgery, respectively. At $24 \mathrm{~h}$, approximately $50 \%$ of the patients reported that their pain was unchanged or had worsened. 
Table 2 Sequelae of anesthesia, attitudes to perioperative care, and postoperative symptoms

\begin{tabular}{|c|c|}
\hline & $n(\%)^{\mathrm{a}}$ \\
\hline \multicolumn{2}{|l|}{ Surgical and anesthetic outcomes } \\
\hline Complications with epidural anesthesia (yes) & $31(17.2)$ \\
\hline Needling $>3$ times $($ yes) & $24(13.3)$ \\
\hline Dural puncture (yes) & $4(2.2)$ \\
\hline Bleeding from epidural space (yes) & $7(3.9)$ \\
\hline Perioperative adverse effects (yes) & $121(67.2)$ \\
\hline Respiratory events (yes) & $17(9.4)$ \\
\hline Cardiac events (yes) & $106(58.9)$ \\
\hline Neurological events (yes) & $5(2.8)$ \\
\hline \multicolumn{2}{|l|}{ Patients' views } \\
\hline \multicolumn{2}{|l|}{ "Feeling safe regarding anesthesia" } \\
\hline Strongly agree & $70(39.3)$ \\
\hline Agree & $105(59.0)$ \\
\hline Neutral & $3(1.7)$ \\
\hline Disagree & $0(0.0)$ \\
\hline Strongly disagree & $0(0.0)$ \\
\hline \multicolumn{2}{|c|}{ "Satisfaction with the preoperative anesthesia education" } \\
\hline Strongly agree & $76(42.7)$ \\
\hline Agree & $100(56.2)$ \\
\hline Neutral & $1(0.6)$ \\
\hline Disagree & $1(0.6)$ \\
\hline Strongly disagree & $0(0.0)$ \\
\hline \multicolumn{2}{|l|}{ "Having good communication with medical staff" } \\
\hline Strongly agree & $86(48.3)$ \\
\hline Agree & $91(51.1)$ \\
\hline Neutral & $1(0.6)$ \\
\hline Disagree & $0(0.0)$ \\
\hline Strongly disagree & $0(0.0)$ \\
\hline \multicolumn{2}{|c|}{ "Having good interactions with family before operation" } \\
\hline Strongly agree & $91(51.1)$ \\
\hline Agree & $86(48.3)$ \\
\hline Neutral & $0(0.0)$ \\
\hline Disagree & $0(0.0)$ \\
\hline Strongly disagree & $1(0.6)$ \\
\hline \multicolumn{2}{|c|}{ "Having good interactions with family after operation" } \\
\hline Strongly agree & $59(33.1)$ \\
\hline Agree & $114(64.0)$ \\
\hline Neutral & $4(2.2)$ \\
\hline Disagree & $1(0.6)$ \\
\hline Strongly disagree & $0(0.0)$ \\
\hline \multicolumn{2}{|l|}{ Postoperative symptoms } \\
\hline \multicolumn{2}{|l|}{ Experienced postoperative symptoms } \\
\hline Dry lips/throat (yes) & $130(73.0)$ \\
\hline Drowsiness (yes) & $78(43.8)$ \\
\hline Sore throat (yes) & $57(32.0)$ \\
\hline Lumbar pain (yes) & $53(29.8)$ \\
\hline Hoarseness (yes) & $40(22.5)$ \\
\hline
\end{tabular}

Table 2 continued

\begin{tabular}{|c|c|}
\hline & $n(\%)^{\mathrm{a}}$ \\
\hline Nausea (yes) & $32(18.0)$ \\
\hline Shoulder pain (yes) & $27(15.2)$ \\
\hline Vomiting (yes) & $25(14.0)$ \\
\hline Headache (yes) & $21(11.8)$ \\
\hline Change in mood (yes) & $16(9.0)$ \\
\hline Shivering (yes) & $13(7.3)$ \\
\hline Fever (yes) & $11(6.2)$ \\
\hline \multicolumn{2}{|c|}{ Total number of postoperative symptoms } \\
\hline$\leq 2$ & $73(41.1)$ \\
\hline$\geq 3$ & $105(58.9)$ \\
\hline \multicolumn{2}{|l|}{ Pain } \\
\hline \multicolumn{2}{|l|}{ Pain expectation } \\
\hline Less than expected & $96(53.9)$ \\
\hline About as expected & $60(33.7)$ \\
\hline More than expected & $22(12.4)$ \\
\hline \multicolumn{2}{|l|}{ Level of pain at $2 \mathrm{~h}^{\mathrm{b}}$} \\
\hline 0 & $6(3.3)$ \\
\hline 1 & $54(30.0)$ \\
\hline 2 & $75(41.7)$ \\
\hline 3 & $40(22.2)$ \\
\hline 4 & $5(2.8)$ \\
\hline 5 & $0(0)$ \\
\hline \multicolumn{2}{|l|}{ Level of pain at $24 \mathrm{~h}^{\mathrm{b}}$} \\
\hline 0 & $19(10.7)$ \\
\hline 1 & $97(54.5)$ \\
\hline 2 & $47(26.4)$ \\
\hline 3 & $14(7.9)$ \\
\hline 4 & $0(0)$ \\
\hline 5 & $1(0.6)$ \\
\hline \multicolumn{2}{|c|}{ Pain reduction between 2 and $24 \mathrm{~h}$} \\
\hline Reduced & $88(49.4)$ \\
\hline Not changed & $66(37.1)$ \\
\hline Worsened & $24(13.5)$ \\
\hline
\end{tabular}

${ }^{\text {a }}$ Total patient cohort $(n)=180$ patients. Discrepancy in the number of patients in some categories is due to two patients being unable to complete the survey as a result of poor postoperative condition

b Pain was measured by a six-level face-scale score. Higher score indicates more severe pain

The bivariate analyses revealed four factors to be associated with the feeling of being less safe with anesthesia; of these, three remained significant when entered together into a multivariate analysis (Table 3): the lack of perioperative adverse effects [odds ratio (OR) $6.10,95 \%$ CI 1.43-26.04], low satisfaction with preoperative anesthesia education (OR 15.03, 95\% CI 4.65-48.55), and low satisfaction with family interactions before and after surgery (OR 21.80, 95\% CI 5.15-92.42). For example, the absence of an adverse effect raises the risk of feeling less safe in 
Table 3 Factors associated with the five main outcomes according to the logistic regression analysis

\begin{tabular}{|c|c|c|c|c|}
\hline \multirow[t]{2}{*}{ Main outcomes } & \multirow[t]{2}{*}{ Significant factors } & \multirow{2}{*}{$\begin{array}{l}\text { Proportion of } \\
\text { the outcome }(\%)\end{array}$} & \multicolumn{2}{|c|}{ Odds ratios ( $95 \%$ confidence intervals) } \\
\hline & & & Bivariate & Multivariate $^{\mathrm{a}}$ \\
\hline \multirow{12}{*}{$\begin{array}{l}\text { Perception of anesthesia } \\
\text { as being less safe }\end{array}$} & \multicolumn{4}{|c|}{ Perioperative adverse effects ${ }^{\mathrm{e}}$} \\
\hline & Yes & $63 / 117(53.8)$ & 1.00 & 1.00 \\
\hline & No & $42 / 58(72.4)$ & $2.25(1.14-4.45)$ & $6.10(1.43-26.04)^{*}$ \\
\hline & \multicolumn{4}{|c|}{ Satisfaction with preoperative anesthesia education } \\
\hline & Strongly agree & $13 / 75(17.3)$ & 1.00 & 1.00 \\
\hline & Do not strongly agree ${ }^{f}$ & $92 / 100(92.0)$ & $54.8(21.47-140.08)$ & $15.03(4.65-48.55)^{*}$ \\
\hline & \multicolumn{4}{|c|}{ Having good communication with medical staff } \\
\hline & Strongly agree & $25 / 85(29.4)$ & 1.00 & 1.00 \\
\hline & Do not strongly agree ${ }^{\mathrm{f}}$ & $80 / 90(88.9)$ & $19.20(8.57-43.00)$ & $2.61(0.76-8.93)$ \\
\hline & \multicolumn{4}{|c|}{ Having good interaction with family before and after surgery } \\
\hline & Strongly agree & $6 / 56(10.7)$ & 1.00 & 1.00 \\
\hline & Do not strongly agree ${ }^{f}$ & $99 / 119(83.2)$ & $41.25(15.58-109.21)$ & $21.80(5.15-92.42)^{*}$ \\
\hline \multirow{3}{*}{$\begin{array}{l}\text { Having } \geq 3 \text { postoperative } \\
\text { symptoms }\end{array}$} & \multicolumn{4}{|l|}{ Duration of surgery } \\
\hline & $<3 \mathrm{~h}$ & $44 / 87(50.6)$ & 1.00 & - \\
\hline & $\geqq 3 \mathrm{~h}$ & $61 / 91(67.0)$ & $2.00(1.08-3.64)$ & - \\
\hline \multirow{6}{*}{$\begin{array}{l}\text { Severe pain }{ }^{\mathrm{c}} \text { at } 2 \mathrm{~h} \\
\text { post-surgery }\end{array}$} & \multicolumn{4}{|l|}{ Sex } \\
\hline & Female & $14 / 80(17.5)$ & 1.00 & 1.00 \\
\hline & Male & $31 / 100(31.0)$ & $2.12(1.04-4.33)$ & $2.08(1.00-4.29)^{*}$ \\
\hline & \multicolumn{4}{|c|}{ Type of surgical procedures } \\
\hline & Laparoscopic surgery & $5 / 45(11.1)$ & 1.00 & 1.00 \\
\hline & Open surgery & $40 / 135(29.6)$ & 3.39 (1.24-9.16) & $3.30(1.21-9.05)^{*}$ \\
\hline \multirow{3}{*}{$\begin{array}{l}\text { No reduction }{ }^{\mathrm{d}} \text { in pain after } \\
\text { surgery }\end{array}$} & \multicolumn{4}{|l|}{ Sex } \\
\hline & Female & $48 / 79(60.8)$ & 1.00 & - \\
\hline & Male & $42 / 99(42.4)$ & $0.48(0.26-0.87)$ & - \\
\hline \multirow{6}{*}{$\begin{array}{l}\text { Feeling pain equal to or } \\
\text { more than expected }\end{array}$} & \multicolumn{4}{|l|}{ Amount of blood loss } \\
\hline & $<100 \mathrm{ml}$ & $23 / 66(34.8)$ & 1.00 & 1.00 \\
\hline & $\geqq 100 \mathrm{ml}$ & $59 / 112(52.7)$ & $1.04(1.01-1.07)$ & $1.04(1.01-1.07) *$ \\
\hline & \multicolumn{4}{|c|}{ Having good communication with medical staff } \\
\hline & Strongly agree & $33 / 86(38.4)$ & 1.00 & 1.00 \\
\hline & Do not strongly agree ${ }^{f}$ & $49 / 92(53.3)$ & $1.83(1.01-3.33)$ & $1.90(1.03-3.49)^{*}$ \\
\hline
\end{tabular}

Fifteen items of sociodemographic characteristics and surgical and anesthetic factors were entered into the analysis of having three or more postoperative symptoms. In the analyses of the other four outcomes, five additional variables of sociodemographic characteristics and patients' views were entered

OR Odds ratio, $C I$ confidence interval

$* p<0.05$

a Multiple logistic regression analysis entering all significant factors in the bivariate logistic regression analysis

b "Agree" was categorized as 'feeling less safe' as opposed to "strongly agree", and the other three categories of "neutral", "disagree", and "strongly disagree" were excluded

c "Severe pain" includes the upper three scores out of six-level face scale scores

d "No reduction" includes worsened and no change in pain between 2 and 24 h post-surgery

e Perioperative adverse effects include cardiovascular, respiratory, neurological, and other adverse effects

f Category includes "agree", "neutral”, "disagree", and "strongly disagree"

anesthesia by 6.1-fold compared to a reference group of patients with adverse effects. Based on the multivariate analysis, good communication with staff did not have a significant effect on patients' perceptions of anesthesia safety (OR 2.61, 95\% CI 0.76-8.93).
With respect to postoperative symptoms, surgery $>3 \mathrm{~h}$ was associated with having three or more postoperative symptoms (OR 2.00, 95\% CI 1.08-3.64). Factors significantly associated with severe pain at $2 \mathrm{~h}$ were male sex (OR 2.08, 95\% CI 1.00-4.29) and open surgery (OR 3.30, 
95\% CI 1.21-9.05). Likewise, male sex was associated with no reduction in pain between 2 and $24 \mathrm{~h}$ post-surgery (OR 0.48 , 95\% CI $0.26-0.87$ ). In terms of feeling pain equal to or more than expected, blood loss $>100 \mathrm{ml}$ (OR $1.04,95 \%$ CI 1.01-1.07) and low satisfaction with communication with medical staff (OR 1.90, 95\% CI 1.03 3.49) were shown to be significant associations. In painrelated subanalyses by gender, open surgery was significantly associated with severe pain at $2 \mathrm{~h}$ (OR 6.34, 95\% CI 1.39-29.06), and evidence of benign disease was associated with no reduction in pain between 2 and $24 \mathrm{~h}$ after surgery (OR $0.27,95 \%$ CI $0.086-0.8$ ) among males.

\section{Discussion}

Clinical assessments and international comparison

This study was performed in Vietnam and is the first study in a developing Southeast Asian country to comprehensively evaluate perioperative care from both the clinical and patient perspective. Through service assessments, analyses of collected data, and the presentation of scientific evidence, health professionals and health policy-makers are able to comprehend, prioritize, and address a country's public health problems [18]. However, a recent systematic review of questionnaires measuring patient satisfaction with anesthesia care [19] shows that a standardized, valid, or reliable survey has yet to be perfected in developed countries [20,21].

To provide additional insight into the interpretation of our results, we compared hospital statistics on surgery and anesthesia from Vietnam with those reported from other East Asian, Southeast Asian, and non-Asian countries (Table 4). Two reports from Italy-one in which classic medical indicators were used [22] and another in which more comprehensive assessment tools were applied, including patient satisfaction and staff mental state [3] - and one each from Hong Kong [11], Thailand [23, 24], and Japan [25] are reported. The proportion of major surgical cases at UMC was approximately the same as that in Italy. Moreover, based on our data, general anesthesia was used at a similar frequency in gastro-intestinal (GI) tract surgeries among developed and newly developed countries, demonstrating the rapidity with which modern anesthesia techniques have been introduced and adopted at a university hospital in Vietnam.

The frequency of perioperative adverse effects and postoperative symptoms identified in our study was nearly the same as that reported in previous studies of developed countries, notably Italy and Canada [16, 22]. Also, significant differences in pain due to different types of anesthesia or analgesia, which may suggest inadequate pain management, were not observed. For sufficient postoperative analgesia, patients without epidural anesthesia (26.1\%) were given morphine intravenously or other painkillers more often than those with epidural anesthesia (73.9\%) (chi-square test, $p<0.01$ ). Moreover, anesthesiologists gave epidural anesthesia more frequently to open surgery patients $(75.0 \%)$, who were expected to have severe postoperative surgical pain, than to laparoscopic surgery patients $(25.0 \%)$ (chi-square test, $p=0.05$ ).

On the negative side, the number of epidural anesthesia complications revealed in our study seems to be relatively high, and the incidence of critical complications (2/180) is higher than that in developed countries [22, 25]. Despite this, one distinct characteristic of this survey was Vietnamese patients' high satisfaction with the services they received, which mostly likely reflects an overall high quality of care. However, this discrepancy is a warning that our results should be interpreted with caution; as has been noted by other authors, patients may be biased by the desire to please staff and to avoid repercussions for appraising care negatively [26]. We therefore explored differences between groups of patients who were "very satisfied" versus "satisfied" with the care they received. A detailed analysis revealed that negative outcomes regarding anesthesia satisfaction and pain were associated with clinical backgrounds, gender, and patients' views on medical care. In the following sections, we explore the relevant clinical and sociodemographic factors that influence perioperative care and patients' perceptions of this care. Based on our findings, we propose specific recommendations for improving not only the quality of clinical care but the twoway communication between staff and patients.

\section{Communication and perception of anesthesia safety}

In terms of the patients' perceptions of anesthesia safety, we found that an insufficient preoperative provision of anesthesia information and a less-than-satisfactory interaction with family before and after surgery were significantly associated with a low sense of safety. These findings suggest that the relationship with both the healthcare staff and family members have a strong influence on a patient's perception of physical well-being, in this case regarding anesthesia care. The results of a previous study showed that patients reported greater satisfaction with care when they perceived the medical staff as showing concern for how much pain they were feeling [27]. Interestingly, the lack of perioperative adverse effects was another factor significantly associated with feeling less safe. It may be possible that a higher level of staff attentiveness towards patients with adverse effects could make them feel more secure. Supporting this hypothesis, Street et al. [28] reported that physicians seeing patients with critical diseases used more partnership-building and supportive talk than physicians seeing patients with less severe conditions. 
Table 4 Comparison of anesthesia assessments at the international level: data collected from the surveyed university hospital in Vietnam and examples of multi-center studies in other countries

\begin{tabular}{|c|c|c|c|c|}
\hline Studies compared & $\begin{array}{l}\text { 1. Country } \\
\text { 2. Subjects } \\
\text { 3. Study duration }\end{array}$ & $\begin{array}{l}\text { Category of } \\
\text { operations }\end{array}$ & Types of anesthesia & Assessment indicators \\
\hline Data from study site & $\begin{array}{l}\text { 1. Vietnam (hospital statistics) } \\
\text { 2. } 13,429 \text { subjects aged } \geq 15 \text { years } \\
\text { 3. One year in } 2005\end{array}$ & $\begin{array}{l}\text { Abdominal } 48 \% \\
\text { ENT } 18 \% \\
\text { Urological } 15 \% \\
\text { Others } 19 \% \\
\text { (laparoscopic } \\
\quad \text { surgery } 30 \% \text { ) }\end{array}$ & $\begin{array}{l}\text { General anesthesia (GA) } 57 \% \\
\text { Major regional anesthesia } \\
\text { (MRA) } 22 \% \\
\text { Others } 21 \%\end{array}$ & \\
\hline $\begin{array}{l}\text { Examples of multi- } \\
\text { center studies }\end{array}$ & $\begin{array}{l}\text { 1. Italy (162 hospitals) } \\
\text { (Peduto et al. 2004) [22] } \\
\text { 2. 12,263 subjects of all ages } \\
\text { 3. One week }\end{array}$ & $\begin{array}{l}\text { Abdominal and } \\
\text { urological } 29 \% \\
\text { Obstetric- } \\
\text { gynecological } \\
20 \% \\
\text { Orthopedic } 14 \% \\
\text { ENT } 10 \% \\
\text { Others } 27 \%\end{array}$ & $\begin{array}{l}\text { Proportion of GA } \\
\text { ENT 95\% } \\
\text { Gynecological } 86 \% \\
\text { Abdominal } 76 \% \\
\text { Urological } 55 \%\end{array}$ & $\begin{array}{l}\text { 1. Demographic items } \\
\text { 2. Medical conditions } \\
\text { including ASA } \\
\text { 3. Perioperative complications } \\
\text { and adverse effects }\end{array}$ \\
\hline & $\begin{array}{l}\text { 1. Italy ( } 6 \text { hospitals) } \\
\text { (Capuzzo et al. 2007) [3] } \\
\text { 2. } 1,290 \text { subjects aged }>18 \text { years } \\
\text { 3. Three months }\end{array}$ & $\begin{array}{l}\text { Minor surgery } 38 \% \\
\text { Moderate surgery } \\
35 \% \\
\text { Major surgery } 27 \%\end{array}$ & $\begin{array}{l}\text { GA } 53 \% \\
\text { MRA } 33 \% \\
\text { GA and MRA } 14 \%\end{array}$ & $\begin{array}{l}\text { 1. Sociodemographic items } \\
\text { 2. Medical condition including } \\
\text { ASA } \\
\text { 3. Provision of anesthesia } \\
\text { service } \\
\text { 4. Mental condition of staff } \\
\text { 5. Patient satisfaction }\end{array}$ \\
\hline & $\begin{array}{l}\text { 1. Thailand (20 hospitals) } \\
\text { (Charuluxananan et al. 2005) } \\
{[23,24]} \\
\text { 2. } 163,403 \text { subjects of all ages } \\
\text { 3. One year }\end{array}$ & $\begin{array}{l}\text { Abdominal } 25 \% \\
\text { Extremities } 22 \% \\
\text { Cesarean } \\
\text { section } 10 \% \\
\text { Perineal-anal } 6 \% \\
\text { Others } 37 \%\end{array}$ & $\begin{array}{l}\text { GA } 68 \% \\
\text { MRA } 28 \% \\
\text { Others } 4 \% \\
\text { (97\% of GA is not combined } \\
\text { with other anesthesia) }\end{array}$ & $\begin{array}{l}\text { 1. Demographic items } \\
\text { 2. Medical conditions } \\
\text { including ASA } \\
\text { 3. Perioperative complications } \\
\text { and adverse effects } \\
\text { 4. Types of staffs and } \\
\text { equipments }\end{array}$ \\
\hline & $\begin{array}{l}\text { 1. Hong Kong (6 hospitals) } \\
\text { (Lau et al. 2001) [11] } \\
\text { 2. } 18,759 \text { subjects of all ages } \\
\text { 3. Two months }\end{array}$ & $\begin{array}{l}\text { Major surgery } 45 \% \\
\text { Intermediate } \\
\text { surgery } 29 \%, \\
\text { Minor surgery } 26 \%\end{array}$ & $\begin{array}{l}\text { GA } 72 \% \\
\text { MRA } 19 \% \\
\text { GA and MRA } 7 \% \\
\text { Others } 2 \%\end{array}$ & $\begin{array}{l}\text { 1. Demographic items } \\
\text { 2. Medical condition including } \\
\text { ASA } \\
\text { 3. Perioperative complications } \\
\text { and adverse effects }\end{array}$ \\
\hline & $\begin{array}{l}\text { 1. Japan (467 hospitals) } \\
\text { (Kawashima et. al. 1999) [25] } \\
\text { 2. } 793,847 \text { subjects of all ages } \\
\text { 3. One year }\end{array}$ & $\begin{array}{l}\text { Laparotomy } 32 \% \\
\text { Extremities } 16 \% \\
\text { Head-neck-ENT } \\
\quad 14 \% \\
\text { Others } 38 \%\end{array}$ & $\begin{array}{l}\text { GA } 51 \% \\
\text { GA and MRA } 31 \% \\
\text { MRA } 17 \% \\
\text { Others } 1 \%\end{array}$ & $\begin{array}{l}\text { Anesthesia related mortality } \\
\text { and morbidity by } \\
\text { 1. Principle cause } \\
\text { 2. Demographic items } \\
\text { 3. Medical condition } \\
\text { including ASA } \\
\text { 4. Surgical site and anesthetic } \\
\text { methods }\end{array}$ \\
\hline
\end{tabular}

ENT Ear, nose, throat

In our study, satisfaction with the quality and degree of communication with the medical staff, which was significant in the bivariate analysis, became non-significant when examined in the multivariate analysis. In contrast, the significance of an absence of perioperative adverse effects demonstrated a manifold increase on the multivariate analysis. These results imply that the occurrence of adverse effects may have actively decreased the strength of the association between patient-staff communication and the feeling of safety with anesthesia-essentially making communication less important in the setting of adverse events. They may also imply that, in the setting of 
postoperative adverse events, patients value medical care via physician attentiveness, rather than more generalized education or staff communication. While these dynamics may have occurred in the postoperative setting, communication with medical staff should ideally be optimized for all patients during the perioperative period from a patient safety and quality-of-care perspective.

For continued improvement in patient-centered perioperative care in developing Southeast Asian countries, medical workers should provide the same degree of perioperative care that is regarded as "standard of care" in the developed nations: sufficient education regarding anesthetic procedures and adequate communication with every patient, despite the presence of cultural barriers that may make transparent and patient-centered communication less common [29, 30]. Moreover, healthcare providers should be cognizant of the increased importance of the family environment for Vietnamese patients, with special attention to its influence on perceptions of perioperative care.

\section{Surgical procedure and patient satisfaction}

In addition to the above communication-related items, three clinical indicators of the invasiveness of the surgery remained significant in the analyses of factors associated with patient satisfaction and pain: duration of surgery, type of surgical procedures, and amount of blood loss were related to postoperative pain and symptoms. Generally, a shortened postoperative hospital stay and faster recovery $[31,32]$ as well as reduced pain [33, 34] are the main advantages of laparoscopic surgery. In this study, there was no significant difference in operating times between patients undergoing open and laparoscopic surgery. As advances continue in medical technology in Vietnam, efforts to shorten surgical duration, minimize blood loss, and reduce invasive surgical methods could improve not only clinical outcomes but also overall patient satisfaction.

\section{Ethnic and gender differences in postoperative pain}

We also investigated various aspects of pain in the perioperative clinical setting: immediate postoperative pain, reduction in pain over a 24 -h postoperative period, and actual pain compared to expected pain. In particular, the proportion of those complaining that their pain was more severe than expected was as low as $12 \%$. Previous crossnational studies [6,35] indicate that ethnically Asian patients, including Vietnamese and Japanese, tended to be more stoic than Caucasians in terms of their perception of pain. A multi-ethnic study in the USA examining analgesic use for 5 days after cholecystectomy reported that milligram equivalents of meperidine were significantly higher in Caucasians (730 mg) versus Japanese $(460 \mathrm{mg}$ ), Chinese
(450 mg), or Filipinos (480 mg) [35]. Another cross-cultural study reported that Vietnamese patients with femoral shaft fractures reported lower levels of pain than American patients after a similar operation [6].

Among our participants, male patients reported feeling more pain immediately after surgery, but they recovered better over the following $24 \mathrm{~h}$ compared to female patients. Sex differences in pain perception and response to opioids have been described in previous studies from North America, Europe, and Japan [36-41]. Although a variety of cultural and societal factors contribute to sex differences in reporting pain, women are at particular risk for chronic pain and have been shown to detect pain more easily and to attenuate it less than men [42, 43]. In addition, physiological sex differences contribute to pain perception, as gonadal steroid hormone production may influence pain intensity and sensitivity to opioid analgesia [41, 44]. The National Institutes of Health Pain Research Consortium emphasizes that the experience of pain for women is distinct from that of men [42]. Our study indicates the need to pay closer attention to treating immediate postoperative pain among male patients while reducing the factors that may lead to chronic pain among female patients. In the stratified analyses by gender, male patients with benign disease had a higher risk of experiencing no reduction in pain between 2 and $24 \mathrm{~h}$ after surgery, corroborating that the aforementioned lack of postoperative adverse effects may be an important factor in diminishing patient satisfaction with perioperative care and feelings of safety.

Although we found no age difference in pain among our subjects, it has been reported in developed countries that younger people tend to report pain more than their elders [44], perhaps due to stoicism that affects the (lack of) willingness of more elderly people to report pain, usage of coping strategies, and adjustment to persistent pain [45]. The markedly skewed age distribution in our sample (92.2\% of the patients were $\geq 40$ years of age) must be taken into account when interpreting our data and may have affected the reporting rates of the variables investigated.

\section{Limitations and conclusions}

There are four major methodological limitations to the study reported here. First, the patients were recruited at a single university hospital preferred by clients with a higher than average socioeconomic status compared to the Vietnamese population in general. Despite this inherent economic bias, however, the majority of patients in this study had no stable source of income and no medical insurance coverage, a rough marker of socioeconomic status. More than one-third of the patients had less than a primary school 
education. In addition, as a first-of-kind study in developing Southeast Asia, the university hospital setting, with its relatively advanced infrastructure, enabled the survey to be carried out with sufficient collaboration among hospital staff and local co-researchers. Furthermore, the limited generalizability does not affect the validity of the results from internal comparisons between groups of patients with different degrees of the five main outcomes. Second, subgroup analysis was difficult due to the small sample size of 180 patients and the rough categorization of diagnosis and surgical procedures. Third, the observation period in this study was only for the first $24 \mathrm{~h}$ after surgery. Multicentered surveys with a larger sample size and longer observation period are required to minimize selection bias, conduct disease- and surgical procedure-specific analyses, and to examine long-term perioperative care, clinical outcomes, and patient satisfaction. Fourth, just by conducting this study we may have exerted an interventional influence over daily practices in operation and recovery rooms. Either intentionally or unintentionally, local staff might have treated patients more attentively during the study, thus resulting in an underestimation of the frequencies of negative anesthesia outcomes. While the results of this study may have played a significant role in raising awareness among medical staff about patient-centered perioperative care, future studies with blinded evaluators and objective pain assessments will enhance the validity of the current findings.

In conclusion, we found that, in the context of developing Southeast Asian healthcare, patients' interactions with their families and medical staff may strongly influence their feelings regarding the safety of anesthesia and postoperative pain, the invasiveness of the surgical intervention influences postoperative pain and symptoms, and the sex of the patient is related to postoperative pain. In terms of being able to improve patient-centered perioperative care among Vietnamese patients, our results indicate that it is important to facilitate preoperative education-oriented communication between staff and patients and to incorporate families into this positive process. Postoperatively, providers should manage patients' pain with an awareness of the importance of gender differences. Our comparison of perioperative care at the international level revealed a rapid movement in Southeast Asia towards medical care at a level on par with that provided in the developed worldas well as a need to obtain and address country-specific factors for further improvement.

Acknowledgments The authors thank Drs. Nguyen Thi Tu Van and Trinh Huu Phuc (Department of Obstetrics and Gynecology, University of Medicine and Pharmacy, Ho Chi Minh City, Vietnam) for their help in survey management and Dr. Nguyen Anh Tuan (University Medical Center, Ho Chi Minh City, Vietnam), Professor Fumio Goto (Gunma University Graduate School of Medicine,
Maebashi City, Japan), and Dr. Akiko Izuha (Fukushima Red Cross hospital, Fukushima City, Japan) for providing helpful advice on protocol development and analyses.

Conflict of interest statement There are no conflicts of interest in this study.

\section{References}

1. May SL, Hardy JF, Taillefer MC, Dupuis G. Patient satisfaction with anesthesia services. Can J Anaesth. 2001;48:153-61.

2. Sindhvananda W, Leelanukrom R, Juajarungjai S. A questionnaire for measuring patient satisfaction to general anesthesia. J Med Assoc Thai. 2003;86:1167-76.

3. Capuzzo M, Gilli G, Paparella L, Gritti G, Gambi D, Bianconi M, et al. Factors predictive of patient satisfaction with anesthesia. Anesth Analg. 2007;105:435-42.

4. Hepner DL, Bader AM, Hurwitz S, Gustafson M, Tsen LC. Patient satisfaction with preoperative assessment in a preoperative assessment testing clinic. Anesth Analg. 2004;98:1099105.

5. Feinstein AR. The need for humanized science in evaluating medication. Lancet. 1972;2:421-3.

6. Carragee EJ, Vittum D, Truong TP, Burton D. Pain control and cultural norms and expectations after closed femoral shaft fractures. Am J Orthop. 1999;28:97-102.

7. Dakik HA, Koubeissi Z, Kleiman NS, Nasrallah A, Sawaya J, Gharzuddine W, et al. Acute myocardial infarction: clinical characteristics, management and outcome in a university medical centre in a developing Middle Eastern country. Can J Cardiol. 2004;20(8):789-93.

8. Anderson BO, Yip CH, Smith RA, Shyyan R, Sener SF, Eniu A, et al. Guideline implementation for breast healthcare in lowincome and middle-income countries: overview of the breast health global initiative global summit 2007. Cancer. 2008;113(8):222143.

9. Tat S, Barr D. Healthcare in the New Vietnam: comparing patients' satisfaction with outpatient care in a traditional neighborhood clinic and a new, western-style clinic in Ho Chi Minh City. Soc Sci Med. 2006;62:1229-36.

10. Morgan PJ, Halpern S, Lam-McCulloch J. Comparison of maternal satisfaction between epidural and spinal anesthesia for elective Cesarean section. Can J Anaesth. 2000;47:956-61.

11. Lau LL, Hung CT, Chan CK, Chow B, Chui PT, Ho B, et al. Anaesthetic clinical indicators in public hospitals providing anaesthetic care in Hong Kong: prospective study. Hong Kong Med J. 2001;7:251-60.

12. Wahl P, Hahnloser D, Chanson C, Givel JC. Laparoscopic and open colorectal surgery in everyday practice: retrospective study. ANZ J Surg. 2006;76:20-7.

13. Holzer A, Jirecek ST, Illievich UM, Huber J, Wenzl RJ. Laparoscopic versus open myomectomy: a double-blind study to evaluate postoperative pain. Anesth Analg. 2006;102:1480-4.

14. Bauer M, Bohrer H, Aichele G, Bach A, Martin E. Measuring patient satisfaction with anaesthesia: perioperative questionnaire versus standardised face-to-face interview. Acta Anaesthesiol Scand. 2001;45:65-72.

15. Apfelbaum JL, Chen C, Mehta SS, Gan TJ. Postoperative pain experience: results from a national survey suggest postoperative pain continues to be undermanaged. Anesth Analg. 2003;97:53440.

16. Chung F, Un V, Su J. Postoperative symptoms 24 hours after ambulatory anesthesia. Can J Anaesth. 1996;43:1121-7. 
17. Wong DL, Baker CM. Pain in children: comparison of assessment scales. Pediatr Nurs. 1998;14:9-17.

18. Global Forum for Health Research. The 10/90 gap report on health research 2003-2004. Geneva: Global Forum for Health Research; 2004.

19. Chanthong P, Abrishami A, Wong J, Herrera F, Chung F. Systematic review of questionnaires measuring patients' satisfaction in ambulatory anesthesia. Anesthesiology. 2009;110(5):1061-7.

20. Auquier P, Pernoud N, Bruder N, Simeoni MC, Auffray JP, Colavolpe $\mathrm{C}$, et al. Development and validation of perioperative satisfaction questionnaire. Anesthesiology. 2005;102(6):1116-23.

21. Caljouw MAA, Beuzekom MV, Boer F. Patient's satisfaction with perioperative care: development, validation, and application of a questionnaire. Br J Anaesth. 2008;100:637-44.

22. Peduto VA, Chevallier P, Casati A. A multicenter survey on anesthesia practice in Italy. Minerva Anestesiol. 2004;70:473-91.

23. Charuluxananan S, Suraseranivongse S, Punjasawadwong Y, Somboonviboon W, Nipitsukarn T, Sothikarnmanee T, et al. The Thai anesthesia incidents study (THAI study) of anesthetic outcomes: I. Description of methods and populations. J Med Assoc Thai. 2005;88(7):S1-13.

24. Charuluxananan S, Punjasawadwong Y, Suraseranivongse S, Srisawasdi S, Kyokong O, Chinachoti T, et al. The Thai anesthesia incidents study (THAI study) of anesthetic outcomes: II. Anesthetic profiles and adverse events. J Med Assoc Thai. 2005;88(7):S14-29.

25. Kawashima Y, Seo N, Morita K, Irita K, Iwao Y, Tsuzaki K, et al. Anesthesia-related mortality and morbidity in Japan (1999). J Anesth. 2002;16:319-31.

26. Tong D, Chung F, Wong D. Predictive factors in global and anesthesia satisfaction in ambulatory surgical patients. Anesthesiology. 1997;87:856-64.

27. Jamison RN, Ross MJ, Hoopman P, Griffin F, Levy J, Daly M, et al. Assessment of postoperative pain management: patient satisfaction and perceived helpfulness. Clin J Pain. 1997;13:229-36.

28. Street RL Jr, Gordon HS, Ward MM, Krupat E, Kravitz RL. Patients' participation in medical consultations: why some patients are more involved than others. Med Care. 2005;43:960-9.

29. Nguyen GT, Barg FK, Armstrong K, Holmes JH, Hornik RC. Cancer and communication in the health care setting: experiences of older Vietnamese immigrants, a qualitative study. J Gen Intern Med. 2008;23(1):45-50.

30. Donnelly TT. Challenges in providing breast and cervical cancer screening services to Vietnamese Canadian women: the healthcare providers' perspective. Nurs Inq. 2008;15(2):158-68.
31. Adachi Y, Shiraishi N, Shiromizu A, Bandoh T, Aramaki M, Kitano S. Laparoscopy-assisted Billroth I gastrectomy compared with conventional open gastrectomy. Arch Surg. 2000;135:806-10.

32. Dedemadi G, Sgourakis G, Karaliotas C, Christofides T, Kouraklis G, Karaliotas C. Comparison of laparoscopic and open tension-free repair of recurrent inguinal hernias: a prospective randomized study. Surg Endosc. 2006;20:1099-104.

33. Ackroyd R, Watson DI, Majeed AW, Troy G, Treacy PJ, Stoddard CJ. Randomized clinical trial of laparoscopic versus open fundoplication for gastro-oesophageal reflux disease. Br J Surg. 2004;91:975-82.

34. Reza MM, Blasco JA, Andradas E, Cantero R, Mayol J. Systematic review of laparoscopic versus open surgery for colorectal cancer. Br J Surg. 2006;93:921-8.

35. Streltzer J, Wade TC. The influence of cultural group on the undertreatment of postoperative pain. Psychosom Med. 1981;43:397-403.

36. Cepeda MS, Carr DB. Women experience more pain and require more morphine than men to achieve a similar degree of analgesia. Anesth Analg. 2003;97:1464-8.

37. Morin C, Lund JP, Villarroel T, Clokie CML, Feine JS. Differences between the sexes in post-surgical pain. Pain. 2000;85:79-85.

38. Rosseland LA, Stubhaug A. Gender is a confounding factor in pain trials: women report more pain than men after arthroscopic surgery. Pain. 2004;112:248-53.

39. Aubrun F, Salvi N, Coriat P, Riou B. Sex- and age-related differences in morphine requirements for postoperative pain relief. Anesthesiology. 2005;103:156-60.

40. Kawagoe I, Sumida T. Sexual differences in effects and side effects of epidural morphine for VATS (video-assisted thoracic surgery). Masui. 2007;56:685-8.

41. Uchiyama K, Kawai M, Tani M, Ueno M, Hama T, Yamaue H. Gender differences in postoperative pain after laparoscopic cholecystectomy. Surg Endosc. 2006;20:448-51.

42. Ochroch EA, Gottschalk A, Troxel AB, Farrar JT. Women suffer more short and long-term pain than men after major thoracotomy. Clin J Pain. 2006;22:491-8.

43. Crombie IK, Davies HT, Macrae WA. Cut and thrust: antecedent surgery and trauma among patients attending a chronic pain clinic. Pain. 1998;76:167-71.

44. Craft RM, Mogil JS, Aloisi AM. Sex differences in pain and analgesia: the role of gonadal hormones. Eur J Pain. 2004;8:397-411.

45. National Aging Research Institute. Pain: age differences. National Aging Research Institute, Parkville, Australia. http:// www.mednwh.unimelb.edu.au. 